\title{
FutureJournal
}

\section{Comportamento do Consumidor Educacional: Seu Perfil e o Processo de Decisão de Compra}

\author{
Alessandra Daiana Schinaider \\ Graduada em Administração pela Universidade Federal de Santa Maria (UFSM), Brasil \\ alessandra_082@hotmail.com \\ Paloma de Mattos Fagundes \\ Professora do Curso de Administração da Universidade Federal de Santa Maria (UFSM), \\ Brasil \\ palomattos@hotmail.com

\begin{abstract}
Anelise Daniela Schinaider
Graduada em Administração pela Universidade Federal de Santa Maria (UFSM), Brasil aneliseschinaider@gmail.com
\end{abstract}

\section{RESUMO}

O estudo do comportamento do consumidor é importante para elaboração das estratégias de marketing da empresa visando atender seu público-alvo, para garantir a satisfação de seus clientes. Neste artigo, o objetivo é analisar o comportamento do consumidor do Centro Universitário Internacional (Uninter) identificando seu perfil e como acontece seu processo de decisão de compra. Foi realizado um estudo de caso com uma pesquisa qualitativoquantitativa e descritiva utilizando a técnica de amostragem não probabilística por conveniência. Verificou-se que o perfil feminino jovem que possui uma vida financeira independente é o principal público-alvo desse centro universitário. Além disso, o comportamento do consumidor educacional enquadra-se em um perfil econômico e de estudante não tradicional tendo seu processo decisório de compra influenciado por diversos fatores culturais, pessoais, sociais e psicológicos. Os resultados permitem entender o comportamento do consumidor educacional do centro universitário, - que auxilia os profissionais de marketing na elaboração de melhores estratégias para atingir esse público.

PALAVRAS-CHAVE: Comportamento do consumidor. Perfil educacional. Processo decisório. Estratégias de marketing. 


\section{Behavioral Educational Consumer: Its Profile and the Purchase Decision Process}

\section{ABSTRACT}

The consumer behavior study is important for the development of the company's marketing strategies to meet your target audience ensuring customer satisfaction. This study aimed to analyze consumer behavior of International University Center - Uninter identifying their profile and as it does their purchasing decision process. It was realized a case study with a qualitative-quantitative search and descriptive using non-probabilistic sampling technique by convenience. It was found that the young female profile that has an independent financial life is the main target audience of this university center. In addition, the educational consumer behavior fits in an economic profile and non-traditional student taking their decision making buying influenced by diverse cultural, personal, social and psychological factors. The results allow us to understand the educational consumer behavior of this university center assisting marketers in developing better strategies to reach this audience.

KEY-WORDS: Consumer behavior. Educational profile. Decision-making process. Marketing strategies. 


\section{INTRODUÇÃO}

Muito se discute a importância do estudo do comportamento do consumidor em diversas áreas do mercado, como na aquisição de produtos alimentícios, vestuário, aparelhos eletrônicos, serviços ou educação, pois a importância de tal estudo faz com que os profissionais de marketing utilizem estratégias para melhorar o fornecimento do produto ou serviço, transformando a necessidade do cliente em satisfação. De acordo com Kotler e Armstrong (2007), o comportamento do consumidor é influenciado por diferentes fatores, sejam culturais, sociais, pessoais, sejam psicológicos. Como consequência, esses fatores influenciam os consumidores no processo decisório de compra de determinado produto ou serviço, como a aquisição de um curso superior presencial ou a distância entre as diversas Instituições de Ensino Superior (IES), por exemplo, nos centros universitários.

De acordo com o Ministério de Educação (MEC, 2015), os centros universitários caracterizam-se pela oferta de cursos de diversas áreas e, além disso, por ser referência no ensino ofertado por seus excelentes profissionais e pelas condições de trabalho acadêmico. A principal característica é que os centros universitários possuem autonomia para criar, organizar e extinguir cursos e programas da educação superior, localizados em sua sede.

Com essa ampliação dos centros universitários e a globalização do ensino, o comportamento do consumidor dos serviços educacionais tem se tornado um desafio para as Instituições de Ensino Superior (IES), pois, de acordo com Paiva (2012, p. 75), é preciso buscar "um equilíbrio sadio entre o foco no aluno, dentro do paradigma aluno-usuário, de forma a torná-lo um cidadão dotado de valores sociais e apto a interagir socialmente".

Para atingir esse equilíbrio, é preciso entender os principais problemas encontrados nos centros universitários, como a evasão de alunos, a insatisfação acerca do ensino ofertado, a falta de comprometimento tanto dos professores quanto dos alunos; destaca-se, 
ainda, o preconceito da sociedade quanto à formação de profissionais em um curso a distância.

Esses problemas enfrentados pelos centros universitários podem ter correlação com o comportamento de seu consumidor, visto que o preconceito da sociedade em admitir um profissional com formação de curso a distância, por exemplo, pode estar relacionado aos fatores culturais da comunidade em que esse centro está inserido ou, ainda, a insatisfação do aluno com o curso e com o próprio centro pode estar relacionada com a falta de estudo do comportamento desse cliente-consumidor.

Além disso, os consumidores de um curso a distância prezam muito pela qualidade desse serviço educacional, visto que vários fatores influenciam na educação a distância, como a tecnologia, a logística de produção e distribuição do material didático, a capacitação da equipe multidisciplinar, tutores, técnicos, entre outros profissionais (Carvalho, 2013).

No presente trabalho, a proposta é analisar o comportamento do consumidor do Centro Universitário Internacional - Uninter, principalmente, identificar seu perfil e avaliar o seu processo de decisão de compra por meio dos diversos fatores que influenciam nessa tomada de decisão. Ressalta-se, ainda, que esse estudo é inédito nesse centro universitário.

O artigo inicia-se com uma breve abordagem sobre 0 comportamento do consumidor, logo em seguida, passa, então, a detalhar os tipos de perfil do consumidor envolvendo o processo de decisão de compra e, por fim, abordam-se os conceitos do consumidor educacional. Em seguida, são apresentados os procedimentos metodológicos, a análise e a interpretação dos resultados e as contribuições finais do estudo.

\section{REVISÃO BIBLIOGRÁFICA}

Nesta seção, são apresentadas as abordagens teóricas que norteiam este estudo. Inicialmente, foi realizada uma abordagem sobre o comportamento do consumidor, logo em seguida, descreveram-se os tipos de perfil do consumidor, envolvendo o processo de decisão de compra e seus principais fatores de influência no comportamento do consumidor e, 
por fim, foi abordado o consumidor educacional, que serviu de base para a pesquisa.

\subsection{O COMPORTAMENTO DO CONSUMIDOR}

Os profissionais de marketing juntamente com os gerentes das empresas têm uma visão mais focada no estudo do comportamento do consumidor buscando entender qual é a razão e a forma pela qual esses consumidores realizam suas compras de produtos e/ou serviços. Churchill e Peter (2007, p. 146) destacam que "para criar valor para os consumidores e lucros para suas organizações, os profissionais de marketing precisam entender por que os consumidores compram certos produtos e não outros".

Dessa forma, a compreensão do comportamento do consumidor é função essencial do marketing, pois o resultado dessa compreensão leva a cumprir plenamente os objetivos atingindo, de forma efetiva, o mercado de bens e serviços apropriados, satisfazendo as necessidades e desejos dos consumidores, e, além disso, colaborando para o sucesso da empresa (Samara \& Morsch, 2005).

Todas e quaisquer informações dos consumidores auxiliam na tomada de decisão de otimização da empresa, na identificação de forças e fraquezas, na definição de mercados e na identificação dos consumidores potenciais. Las Casas (2006, p. 132) destaca que "somente através do entendimento deste processo será possível viabilizar produtos e serviços que atendam exatamente aos desejos e necessidades dos consumidores".

Churchill e Peter (2007, p. 146) conceituam comportamento do consumidor como "os pensamentos, sentimentos e ações dos consumidores e as influências sobre eles que determinam mudanças". Ou seja, esses fatores que influenciam os consumidores a efetuarem uma compra são bem variáveis e bastante complexos, pois não há um padrão de reação de cada consumidor diante de determinado produto ou serviço que ele está adquirindo e as influências que o levam a comprar podem ser pessoais, psicológicas, sociais e culturais, e também podem variar de acordo com o meio em que vive esse consumidor. 
Para Limeira (2008), o comportamento do consumidor nada mais é que uma sincronia de diversas reações ou até mesmo respostas de estímulos provocados pelos próprios indivíduos visto que esses estímulos são decorrentes de fatores pessoais, ambientais, situacionais e de marketing.

Samara e Morsch (2005) destacam que o consumidor deve ser visto e estudado como um iceberg: o consumidor está no mercado, com ele se relaciona e todos podem vê-lo como a ponta de um iceberg; mas as reais e mais profundas intenções desse consumidor estão ocultas, ou seja, a maior parte do iceberg está submersa e é aí que se encontram os fatores que levam a seu processo decisório de compra e justificam seu comportamento.

A comparação do comportamento do consumidor a um iceberg revela que os profissionais de marketing devem estar preparados para estudar as influências submersas, pois é nessa parte que estão envolvidos os principais fatores de influência da compra de um produto. É nessa parte que se concentram as crenças, os reais valores, o psicológico e os sentimentos mais profundos que impulsionam à compra.

\subsection{PERFIS DO COMPORTAMENTO DO CONSUMIDOR E SEU PROCESSO DECISÓRIO DE COMPRA}

Para entender o perfil do consumidor, é necessário entender como acontece o processo de decisão de compra do consumidor e suas etapas, e, então, os perfis dos consumidores. Menezes (2010) destaca que a tomada de decisão de compra é um momento muito importante para o consumidor e é através dela que os profissionais de marketing poderão entender como esses consumidores agem, pensam e o que influencia seu comportamento.

Para o estudo do comportamento do consumidor, a tomada de decisão de compra refere-se à comparação entre marcas, preço, disponibilidade e a forma de conquistar o consumidor à compra daquele produto que visa satisfazer sua necessidade.

Dias (2003, p. 79) destaca que no mercado de consumo existem cinco fases para o processo de decisão de compra "reconhecimento da necessidade, busca de informações, avaliação das alternativas, escolha 
(compra) e análise pós-compra". As características de cada fase desse processo são apresentadas no Quadro 1.

\begin{tabular}{|l|l|}
\hline \multicolumn{1}{|c|}{$\begin{array}{c}\text { Etapas do processo de decisão de } \\
\text { compra }\end{array}$} & \multicolumn{1}{c|}{ Características } \\
\hline Reconhecimento da necessidade & $\begin{array}{l}\text { Pode estar relacionado ao reconhecimento de uma } \\
\text { sensação interna (fome) ou uma sensação externa } \\
\text { (convite para um casamento). }\end{array}$ \\
\hline Busca de informações & $\begin{array}{l}\text { O processo de busca de informações pode ocorrer de } \\
\text { cinco fontes principais: } \\
\text { - internas (informações armazenadas na memória do } \\
\text { consumidor); } \\
\text { - de grupos (consultar amigos ou familiares); } \\
\text { - de marketing (consultar propagandas, vendedores, } \\
\text { embalagens de produtos); } \\
\text { - públicas (incluem artigos na mídia referentes ao } \\
\text { produto ou serviço que o consumidor procura); } \\
\text { - de experimentação (experimentar o produto). }\end{array}$ \\
\hline Avaliação das alternativas & $\begin{array}{l}\text { Os consumidores tentam identificar a compra que Ihe } \\
\text { trará maior valor percebido. }\end{array}$ \\
\hline Escolha (compra) & $\begin{array}{l}\text { Envolve os seguintes questionamentos: o que } \\
\text { comprar, onde, quando comprar e como pagar. }\end{array}$ \\
\hline Análise pós-compra & $\begin{array}{l}\text { É levado em consideração se o consumidor ficou } \\
\text { satisfeito ou não com a experiência da compra do } \\
\text { produto ou serviço. }\end{array}$ \\
\hline
\end{tabular}

\section{Quadro 1: Análise do processo de decisão de compra}

Fonte: adaptado de Churchill e Peter (2007 pp. 146-151)

As etapas do processo de decisão de compra são essenciais para a escolha de um produto ou serviço. Ao reconhecer a necessidade de comprar um produto, automaticamente o consumidor busca informações acerca do produto, avalia a melhor alternativa de compra (preço, qualidade, disponibilidade do produto), escolhe o produto que mais Ihe atrai a atenção e, então, após a experimentação do produto, analisa se sua necessidade inicial foi satisfeita.

Além disso, o que influencia o processo de tomada de decisão está relacionado a fatores sociais, culturais, psicológicos e pessoais do comportamento do consumidor. Schiffman e Kanuk (2012) apresentam quatros modelos diferentes de consumidores por meio de visões da tomada de decisão. Esses modelos têm como objetivo apresentar uma visão geral ou ainda entender por que e como os consumidores se comportam, traçando seus perfis.

A análise do perfil dos consumidores envolve também a avaliação de renda, faixa etária, gênero, estado civil, escolaridade, cidade de residência, 
motivo que levou o consumidor a adquirir o serviço educacional. É com essas informações que o perfil dos consumidores pode ser identificado, a partir dos quatro tipos de perfis elencados por Schiffman e Kanuk: econômico (faz suas compras de forma racional, analisando custo, tempo, vantagens e desvantagens); passivo (geralmente compra por impulso, sem perceber se é necessária ou não aquela compra); cognitivo (faz suas compras de forma tradicional, respeitando suas crenças); e emocional (costuma envolver seus sentimentos na hora da compra).

Outra classificação de perfis está relacionada ao próprio consumidor educacional. Alfinito e Torres (2008, citados por Oliveira, 2010) destacam três tipos de consumidores educacionais que podem ser identificados no ensino superior: estudantes tradicionais, estudantes não tradicionais e estudantes de primeira geração. Para melhor compreensão, no Quadro 2, apresentam-se esses três tipos de consumidores educacionais e suas principais características.

\begin{tabular}{|c|c|}
\hline $\begin{array}{c}\text { Tipos de consumidores } \\
\text { educacionais }\end{array}$ & Características \\
\hline Estudantes tradicionais & $\begin{array}{c}\text { Eles apenas estudam e não trabalham, têm entre } \\
18 \text { e } 24 \text { anos e acabaram de sair do ensino } \\
\text { médio. }\end{array}$ \\
\hline Estudantes não tradicionais & $\begin{array}{c}\text { Têm família, trabalham e concluíram o ensino } \\
\text { médio há muitos anos. Geralmente têm } 25 \text { anos } \\
\text { ou mais. }\end{array}$ \\
\hline Estudantes de primeira geração & $\begin{array}{c}\text { São os primeiros da família a ingressar em um } \\
\text { curso superior, visto que seus pais têm uma } \\
\text { formação acadêmica inferior à dos próprios filhos. } \\
\text { Dessa forma, eles agem como se estivessem } \\
\text { solucionando um problema de geração familiar. }\end{array}$ \\
\hline
\end{tabular}

\section{Quadro 2: Tipos de consumidores educacionais no ensino superior}

Fonte: adaptado de Alfinito e Torres (2008, citados por Oliveira, 2010, p. 57)

No Quadro 2, apresenta-se como é identificável cada tipo de consumidor educacional por idade e por suas características pessoais e sociais envolvendo a família e o trabalho. Essas características são essenciais para a formulação das estratégias de marketing a fim de atingir o público-alvo de uma Instituição de Ensino Superior.

\subsection{O CONSUMIDOR EDUCACIONAL}


O consumidor educacional é um consumidor diferenciado, pois, ao mesmo tempo que consome um serviço, consome os produtos incluídos nesse serviço, como materiais didáticos, biblioteca, infraestrutura. Paiva (2012) explica que no ambiente educacional existe um duplo comportamento do consumidor: um deles é quando o aluno tem suas vontades e desejos atendidos sem prejuízo de sua aprendizagem em um curso consumindo um serviço básico da educação; e outro comportamento acontece quando o aluno usufrui da biblioteca, da secretaria, da infraestrutura da instituição, consumindo um serviço suplementar da educação.

Neste sentido, a área de educação tem significativa importância na vida do consumidor, que, atualmente, opta por vários motivos por um curso superior e está mais exigente em relação à qualidade e ao resultado final do curso devido à competição do mercado de trabalho.

Esse mesmo consumidor pode ser segmentado de diferentes formas de acordo com cada objetivo da instituição de ensino. Algumas instituições de ensino têm o foco naquele consumidor que apenas deseja acrescentar algo mais a sua formação profissional, então essa instituição tem foco na oferta de cursos de especialização em áreas específicas. Enquanto outras podem segmentar seu público que está se formando no ensino básico ( ${ }^{\circ}$ grau), oferecendo os cursos de graduação e proporcionando a esses consumidores a primeira oportunidade de frequentar um curso orientado para a formação profissional desejada (Paiva, 2012).

Com esse foco, as Instituições de Ensino Superior (IES) podem definir seu público-alvo de acordo com os perfis dos estudantes, conforme Alfinito e Torres (2008, citados por Oliveira, 2010) destacam no Quadro 2, e, além disso, podem focar no tipo de serviço educacional que desejam prestar para a sociedade.

\section{PROCEDIMENTOS METODOLÓGICOS}

Primeiramente foi realizada uma pesquisa bibliográfica com característica exploratória a fim de conhecer melhor o tema proposto. 
Conforme Fachin (2002), a pesquisa bibliográfica envolve todo tipo de obra - revistas, livros, jornais, internet, entre outras.

Este estudo classifica-se como uma pesquisa qualitativoquantitativa. A abordagem qualitativa envolve uma pesquisa literária com os principais autores que abordam este assunto; a abordagem quantitativa tem como objetivo analisar detalhadamente os dados e transformá-los em informações significativas para a pesquisa com questionário de questões fechadas e abertas, usando ferramentas de análise estatística.

Michel (2009, p. 39) trata esse tipo de pesquisa como "quali-quanti" a qual "permite levantar atitudes, pontos de vista, preferências que as pessoas têm a respeito de determinados assuntos, fatos de um grupo definido de pessoas", neste último caso, grupo de alunos matriculados no Centro Universitário Uninter.

Do ponto de vista de seus objetivos, vem a ser uma pesquisa descritiva envolvendo a coleta de dados por meio de questionários padronizados. Gil (1989) destaca que esse tipo de pesquisa envolve o levantamento da identificação do perfil do questionado, como idade, escolaridade, sexo. O autor ainda destaca que a pesquisa descritiva tem relação com a pesquisa exploratória quando aplicada nos serviços educacionais, pois envolve uma preocupação social e prática.

O método de procedimento técnico foi por meio de um estudo de caso. Fonseca (2002, citado por Gerhardt e Silveira, 2009) caracteriza o estudo de caso como uma situação bem definida como uma entidade, escola ou uma unidade social em que se visa entender de forma profunda como e por que acontece tal situação, suas características e sua importância.

Para a realização da pesquisa, foi necessário definir um método de amostragem e delimitar o universo da pesquisa. De acordo com MatiasPereira (2012, p. 92), a "população é a totalidade de indivíduos que possuem as mesmas características definidas para um determinado estudo".

Neste caso, o Centro Universitário Uninter conta com mais de 150 mil alunos atendidos entre os 443 polos de apoio presencial espalhados em todo o Brasil. A população deste estudo de caso é de 433 alunos, os quais 
estão matriculados em cursos de graduação e pós-graduação a distância no Centro Universitário Uninter - Polo de Palmeira das Missões/RS.

Dessa forma, o método de amostragem é não probabilístico por conveniência, ou seja, a seleção da amostra é com base nos alunos matriculados especificamente apenas no Centro Universitário Uninter - Polo de Palmeira das Missões/RS com base na facilidade de contato com esses alunos, atingindo um público de 60 respondentes. De acordo com Silva (2005, p. 14), esse tipo de amostragem "é constituída por unidades selecionadas da população objetivo por algum critério de conveniência, muito frequentemente relacionado à acessibilidade das unidades"; além disso, esse tipo de amostra costuma ser mais barata e rápida.

Para este estudo, foi construído um questionário como instrumento de coleta de dados com sequências de perguntas fechadas e pergunta aberta a fim de identificar o perfil do consumidor educacional na empresa em que foi aplicado o questionário e também analisar o comportamento do consumidor em seu processo decisório de compra.

O questionário contou com 23 questões, dentre elas 16 fechadas de múltipla escolha; duas com questões fechadas, em que se pode marcar mais de uma alternativa; duas questões envolvendo a Escala Likert - uma contava com nove afirmações referentes aos graus 1 (Discordo totalmente) - 5 (Concordo totalmente) e outra com 13 afirmações referentes aos graus 1 (Muito insatisfeito) - 5 (Muito satisfeito); e três perguntas abertas. 0 questionário foi elaborado com base em Oliveira (2010) e sofreu algumas adaptações para a pesquisa.

A forma de elaboração e aplicação do questionário foi através do Google.Docs e enviado o endereço URL para todos os alunos matriculados no Centro Universitário Uninter - Polo de Palmeira das Missões/RS pelo email do Polo e, depois de duas semanas, foi enviado também via chat através de uma rede social. Todo esse processo desenvolveu-se no período de 17 de agosto a 22 de setembro de 2015, quando os alunos estavam em provas presenciais no Polo, mencionando-se a eles a importância de responderem o questionário e o cumprimento do prazo, conforme descrito no e-mail e nas mensagens do chat. 
Após a coleta, os dados foram tabulados com o uso de softwares específicos para tal análise. Lakatos e Marconi (2010, p. 150) definem que a tabulação "é a disposição dos dados em tabelas, possibilitando maior facilidade na verificação das inter-relações entre eles".

Neste caso, a tabulação foi mecânica utilizando o software LibreOffice com código aberto e gratuito. O estudo dos dados foi feito por meio de análise descritiva com aplicação de questionários envolvendo métodos estatísticos e uma análise exploratória das questões abertas de modo qualitativo.

Lakatos e Marconi (2010) destacam que a análise e a interpretação dos dados ocorrem de forma distinta, enquanto a primeira busca a explicação entre causa e efeito, a segunda refere-se à atividade intelectual e busca respostas significativas vinculadas a outros conhecimentos.

A análise ocorreu por meio da tabulação e apresentação dos dados com o desenvolvimento de tabelas e gráficos e, logo após, a interpretação desses dados gerando informações significativas para a pesquisa.

\section{APRESENTAÇÃo E ANÁLISE DOS RESULTADOS}

Primeiramente, são feitas a caracterização do consumidor do Centro Universitário Uninter - Polo de Palmeira das Missões/RS e a definição do seu perfil, e, logo após, define-se seu processo de decisão de compra com os principais fatores que influenciam o comportamento deste consumidor.

\subsection{CARACTERÍSTICAS DO PERFIL DO CONSUMIDOR EDUCACIONAL}

A seguir é analisado o perfil do consumidor educacional através das características pessoais, psicológicas, sociais e culturais, apresentando-se os resultados em porcentagens das características que mais foram destacadas nos alunos respondentes, conforme é exibido na Tabela 1. 


\section{Tabela 1: Caracterização do consumidor do Centro Universitário Uninter}

\begin{tabular}{|c|c|c|}
\hline CARACTERÍSTICAS DO PERFIL & $\begin{array}{l}\text { FREQUÊNCIA } \\
\text { ABSOLUTA (FA) }\end{array}$ & $\begin{array}{l}\text { FREQUÊNCIA } \\
\text { RELATIVA (FR) }\end{array}$ \\
\hline Sexo: feminino & 46 & $77 \%$ \\
\hline Faixa etária: jovem-adulta (até 35 anos de idade) & 37 & $62 \%$ \\
\hline Estado civil: casados & 27 & $45 \%$ \\
\hline $\begin{array}{l}\text { Escolaridade antes de ingressar no centro: ensino } \\
\text { médio completo }\end{array}$ & 45 & $75 \%$ \\
\hline Município de residência: Palmeira das Missões/RS & 49 & $82 \%$ \\
\hline Constituição da família: pequena (apenas um filho) & 21 & $66 \%$ \\
\hline $\begin{array}{l}\text { Contribuição na renda familiar: trabalham e são } \\
\text { responsáveis pelo sustento da família }\end{array}$ & 33 & $55 \%$ \\
\hline $\begin{array}{l}\text { Renda mensal: até três salários mínimos (classes C e } \\
\text { D) }\end{array}$ & 36 & $61 \%$ \\
\hline $\begin{array}{l}\text { Curso dos alunos respondentes: Licenciaturas em } \\
\text { Geografia, História, Letras, Matemática e Pedagogia }\end{array}$ & 35 & $58 \%$ \\
\hline Acesso à Internet: em casa e no trabalho & $\begin{array}{l}56 \\
38\end{array}$ & $\begin{array}{l}93 \% \\
66 \%\end{array}$ \\
\hline $\begin{array}{l}\text { Tempo gasto navegado na Internet por dia: máximo } \\
\text { cinco horas }\end{array}$ & 27 & $45 \%$ \\
\hline
\end{tabular}

Fonte: elaborada pelas autoras

A partir da análise de todas essas características, percebe-se que o consumidor do Centro Universitário Internacional - Uninter - Polo de Palmeira das Missões/RS resulta em um público-alvo feminino jovem, com uma faixa etária de até 35 anos, casadas e com família. Sua última formação foi o ensino médio antes de ingressar na Uninter e 82\% moram em Palmeira das Missões, mesma cidade do Polo.

Além disso, mais da metade desse público trabalha e é responsável pelo sustento da família, possuindo uma renda mensal que gira em torno de dois ou três salários mínimos, que o encaixa nas classes $C$ e D da sociedade.

Esse público com classes sociais baixas justifica-se pelas diversas oportunidades de fácil acesso ao estudo implantadas pelo governo, possibilitando o acesso dessa população precária ao ensino superior. Com esse fator, Ryon Braga (2009, citado por Oliveira, 2010) destaca que as universidades que possuem mensalidades mais baixas têm uma taxa de crescimento de seu lucro bem maior do que as universidades com mensalidades mais altas.

Ainda tem-se o dado de que os alunos dos cursos de licenciaturas são mais participativos quando o assunto envolve a contribuição para 
desenvolvimento de uma pesquisa, o que justifica os mais de $50 \%$ de alunos respondentes e, também, pode-se elencar, o fato de haver 160 alunos matriculados nesses cursos, representando $37 \%$ do total de alunos matriculados no Polo.

O acesso à Internet não é empecilho para esse público que deseja alavancar em sua carreira profissional, pois mais de $90 \%$ dos alunos entrevistados têm acesso à internet em casa e mais da metade em seu ambiente de trabalho. Quanto à sua navegação, ficam em torno de uma a cinco horas conectados à rede diariamente, pois, de fato, realizam curso a distância em que a aprendizagem acontece de forma virtual.

Ao analisar o tipo de visão na tomada de decisão dos alunos, conforme os autores Schiffman e Kanuk (2012), questionou-se aos respondentes em qual perfil eles melhor se encaixavam quando estavam envolvidos no processo de decisão de compra, ou seja, quando eles realizavam as compras, conforme é apresentado na Figura 1.

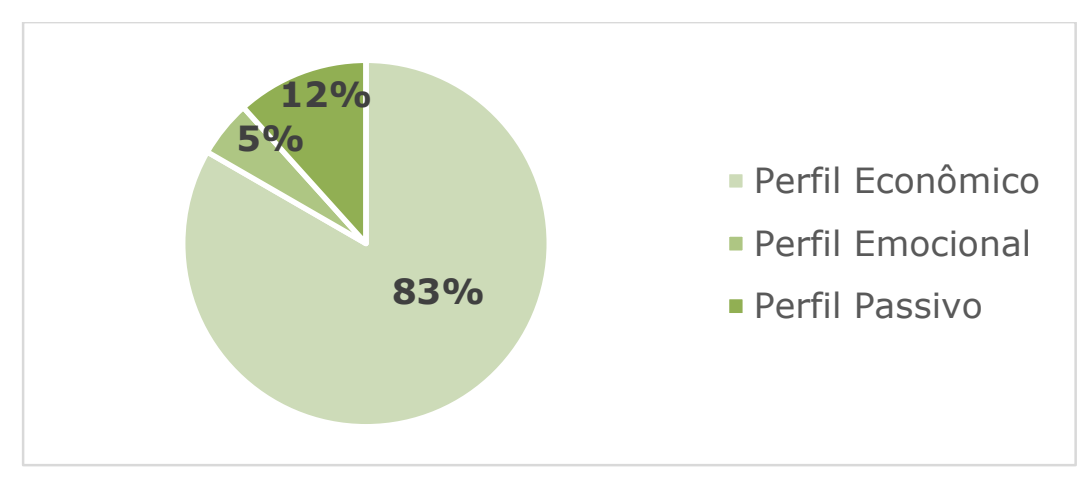

\section{Figura 1: Perfil dos alunos de acordo com seu processo de decisão de compra}

Fonte: elaborada pelas autoras

Schiffman e Kanuk (2012) apresentam quatro tipos de perfis através das visões da tomada de decisão do consumidor: perfil econômico, perfil emocional, perfil passivo e perfil cognitivo. Conforme os resultados, $83 \%$ dos respondentes se encaixam no Perfil Econômico; 12\%, no Perfil Passivo; e 5\%, no Perfil Emocional.

O Perfil Cognitivo não teve nenhum respondente, o que denota que, no processo de decisão de compra para os dias atuais, os alunos não realizam um processo mental envolvendo a tradição ou a crença como forma influenciadora na compra de um produto ou serviço. 
Na Figura 2, é apresentado o perfil educacional dos alunos do Centro Universitário Uninter - Polo de Palmeira das Missões/RS, de acordo com Alfinito e Torres (2008, citados por Oliveira, 2010).

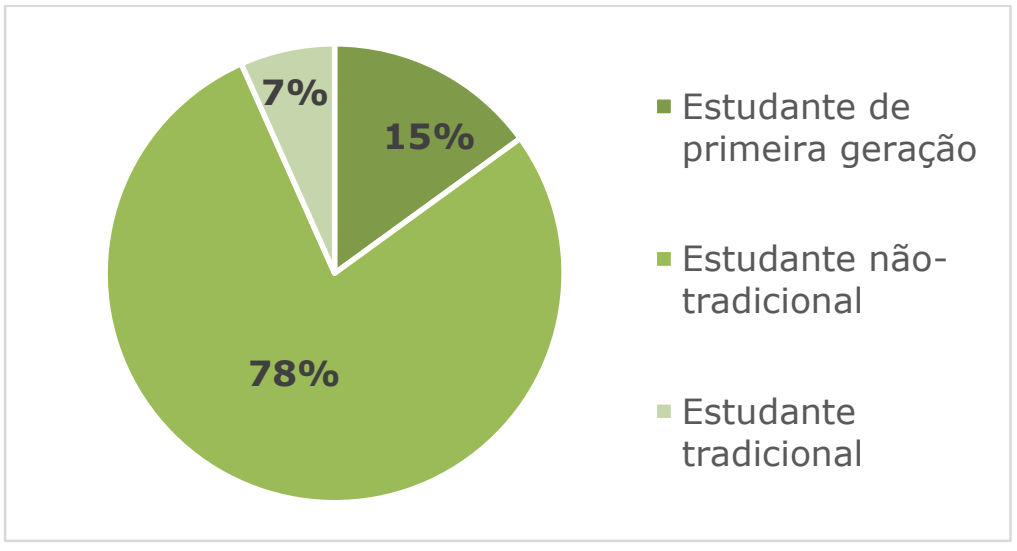

Figura 2: Perfil educacional dos alunos

Fonte: elaborada pelas autoras

Neste caso, $78 \%$ dos respondentes enquadram-se no perfil de estudante não tradicional, que possui família, trabalha e ainda estuda; $15 \%$ são estudantes de primeira geração, ou seja, são os primeiros da família em busca de sua graduação; e 7\% são estudantes tradicionais, aqueles que acabaram de sair do ensino médio e somente estudam.

Dessa forma, o perfil do consumidor do Centro Universitário Uninter - Polo de Palmeira das Missões/RS, é o estudante não tradicional e econômico, o que justifica os dados anteriores referentes à caracterização dos perfis dos alunos (faixa etária, renda, tipo de família, sexo).

\subsection{PROCESSO DE DECISÃO DE COMPRA DO CONSUMIDOR EDUCACIONAL}

Os fatores culturais, sociais, psicológicos e pessoais estão associados ao processo de escolha da Instituição de Ensino Superior e do próprio curso em que o aluno estuda. Por meio de questões elaboradas para avaliar todas as etapas do processo decisório de compra desses alunos, tem-se o resultado apresentado na Figura 3.

Nesse processo, são avaliadas todas as alternativas e possibilidades que têm influência na tomada de decisão desse consumidor, consequentemente definindo sua tomada de decisão como consumidor 
educacional. Esse processo é analisado de acordo com as fases do processo de decisão de compra descritas por Churchill e Peter (2007).

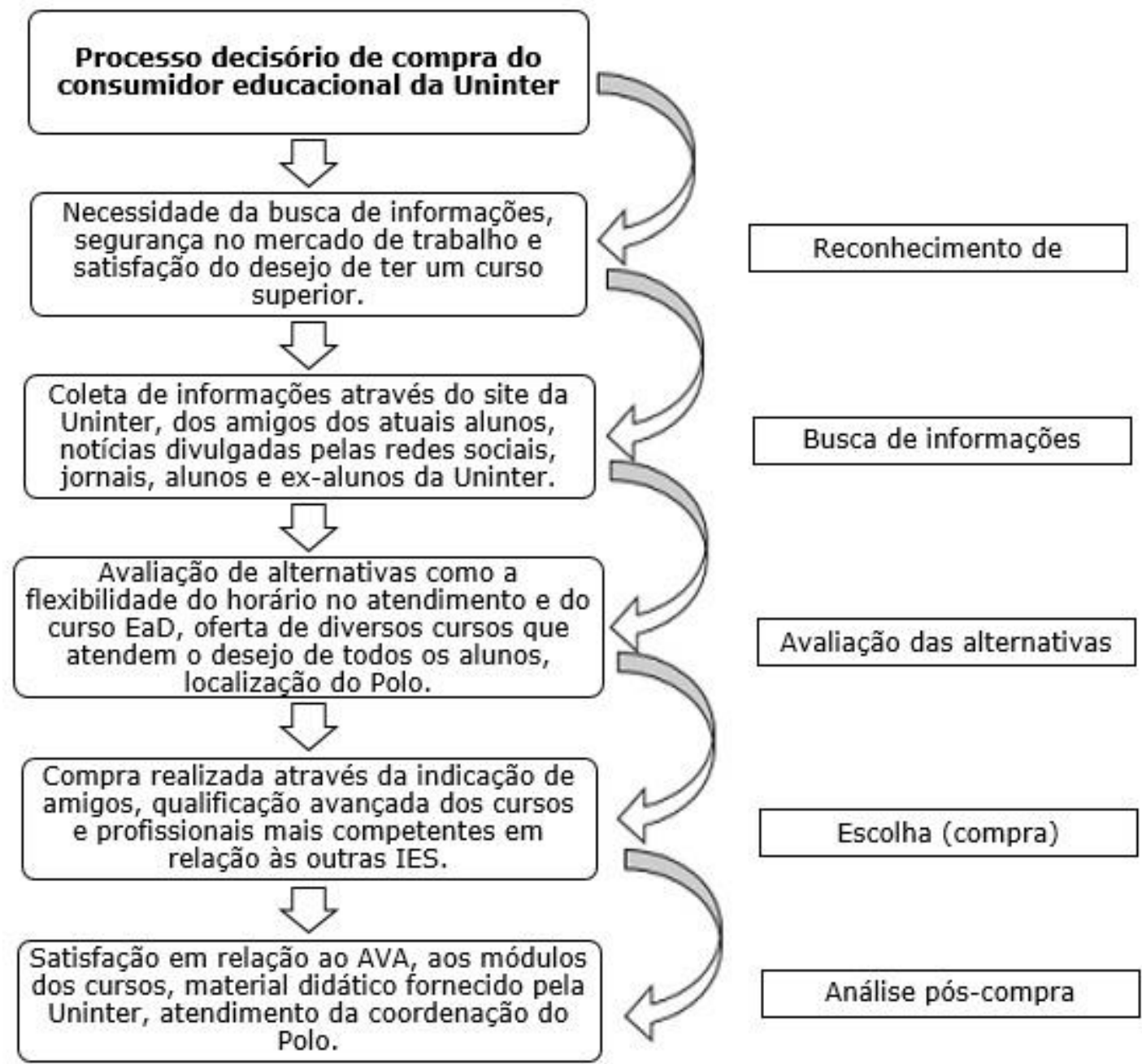

\section{Figura 3: Processo decisório de compra do consumidor educacional da Uninter}

Fonte: elaborada pelas autoras

Percebe-se que o reconhecimento de realizar um curso na Uninter vincula-se a buscar novas informações, novos conhecimentos, além disso, a busca por um emprego e a possibilidade de garantir estabilidade e sustento da família, ou seja, garantir a segurança e, além do mais, a satisfação de realizar um curso superior atendendo esse desejo pessoal.

A busca de informações ocorre nos mais diversos meios, mas os principais são o site do Centro Universitário Uninter, amigos dos atuais alunos do centro, notícias divulgadas pelas redes sociais ou jornais, ou, ainda, informações obtidas por meio de alunos ou ex-alunos do centro. Quando o consumidor analisa todas as informações e, então, opta pelo 
Centro Universitário Uninter- Polo de Palmeira das Missões, as principais alternativas que fizeram parte de seu processo decisório foram a flexibilidade de horário do atendimento do Polo e dos cursos EaD que o centro oferece, as várias opções de cursos que o centro oferece e sua localização.

A compra definitiva de um curso do Centro Universitário Uninter tem um peso ainda maior quando é indicado por meio de amigos que já fizeram algum curso nesse centro, e atestam a qualificação avançada dos cursos e também dos profissionais, mais competentes em relação aos das outras Instituições de Ensino Superior.

A análise pós-compra apresenta um feedback do consumidor final, revelando se ele realmente ficou satisfeito com o produto ou serviço. Neste caso, o consumidor educacional da Uninter está satisfeito com os serviços relacionados ao Ambiente Virtual de Aprendizagem, aos módulos dos cursos, ao material didático fornecido pela Uninter e ao atendimento por parte da coordenação do Polo.

O consumidor da Uninter é atento para diversos fatores que influenciam sua tomada de decisão de compra, desde a busca pela satisfação pessoal em frequentar o curso que realmente deseja, assim como a melhor forma de poder realizar esse curso buscando a modalidade a distância. Nascimento, Jimenez e Campomar (2014, p. 35) destacam que "é necessário mapear o que é valorizado pelo cliente e destacar os atributos relevantes para definir uma estratégia que leve em conta suas necessidades, suas expectativas e seus desejos".

Nesse sentido, entender o processo decisório de compra do consumidor educacional faz com que os profissionais de marketing e os próprios gestores das IES compreendam o perfil desse consumidor. Oliveira (2010) destaca que, além de acontecer essa compreensão, é necessário a instituição adaptar-se às necessidades desse consumidor.

\section{CONSIDERAÇÕES FINAIS}

A presente pesquisa buscou analisar o comportamento do consumidor do Centro Universitário Internacional - Uninter, localizado no 
município de Palmeira das Missões/RS, identificando seu perfil e como ocorre seu processo de decisão de compra de um serviço educacional. Os resultados evidenciam que o principal público da Uninter são as mulheres com uma faixa etária jovem, casadas e com família, as quais buscam o sustento da família por meio do próprio trabalho.

A pesquisa contribui fundamentalmente para o campo dos estudos do comportamento do consumidor dos serviços educacionais que as diversas Instituições de Ensino Superior oferecem ao público. A identificação do perfil do consumidor educacional faz com que os profissionais de marketing elaborem melhores estratégias a fim de atingir esse público. No caso da Uninter, sugere-se, como uma dessas estratégias, divulgar esses serviços em escolas que oferecem $02^{\circ}$ grau do ensino médio na modalidade de magistério, assim esses alunos poderão interessar-se pelos cursos de licenciaturas, visto que são os cursos que mais apresentam alunos matriculados.

Juntamente com a identificação desse perfil, autores como Schiffman e Kanuk (2012) e Alfinito e Torres (2008, citados por Oliveira, 2010) elaboraram teorias vinculadas aos perfis do consumidor buscando analisar qual visão o consumidor possui ao tomar a decisão de compra de um produto ou serviço e o perfil educacional relacionado com algumas características que esses consumidores apresentam.

Os consumidores da Uninter - Polo de Palmeira das Missões/RS tomam suas decisões com uma visão econômica diante dos produtos ou serviços oferecidos no mercado. Eles buscam analisar todos os detalhes de uma compra, o que é justificado por seu próprio perfil educacional, que é o estudante não tradicional, que estuda, trabalha e sustenta a família, envolvendo-se em todas as etapas do processo de decisão de compra. 0 público feminino da Uninter são aquelas mulheres que concluíram o ensino médio há alguns anos, possuem família, trabalham e lutam para ingressar no curso superior de seus sonhos.

O perfil desse aluno é o de quem costuma avaliar a flexibilidade de horários no atendimento e do próprio curso EaD, pois, como ele trabalha, o curso a distância facilita o progresso do seu ensino. Nesse sentido, propõese divulgar os cursos da Uninter do Polo de Palmeira das Missões nas 
empresas da cidade e de outros municípios, por meio de folders, oferecimentos de brindes, como canetas e adesivos dos cursos e da instituição, e propor o convite de realizar um passeio pelo Polo para conhecer sua estrutura e participar de uma aula experimental do curso desejado, através de agendamento para os finais de semana ou à noite. Desse modo, é possível proporcionar maior flexibilidade de horário ao aluno e ele poderá ter profundo conhecimento e informação do seu curso e da instituição antes de efetuar a matrícula.

Além de a Uninter possuir esse público no ensino, nota-se que no processo decisório diversos fatores de influência são analisados por parte dos consumidores educacionais desde o reconhecimento da necessidade de buscar um curso profissional até a satisfação de ter adquirido esse curso.

Sugere-se que os profissionais de marketing desenvolvam a divulgação de seus serviços de ensino para esse público, atingindo os principais fatores que levam esses consumidores a efetuar a compra, como, a oferta de cursos de licenciaturas, os quais são os mais procurados pelo perfil desse público, com descontos na matrícula.

A busca de informações costuma ser feita pelo site do Centro Universitário ou com alunos ou ex-alunos da Uninter. Para intensificar essa busca, pode-se proporcionar uma diferente forma de pagamento para os atuais alunos, como o pagamento da matrícula para o próximo módulo com desconto, desde que eles indiquem futuros alunos para realizar o vestibular da Uninter e no momento da inscrição esse vestibulando poderá ressaltar quem foi sua fonte de informação.

Além disso, sugere-se criar uma página do Polo em uma rede social para maior divulgação online dos cursos, dos períodos dos vestibulares, dos horários de atendimento do Polo e avisos e comunicados em geral do Polo. Drubscky (2015) afirma que há maior viralização de conteúdo através da rede social, que atinge elevados níveis de transmissão de conteúdos.

Para fidelizar esse público, propõe-se ao Polo realizar, juntamente com o Grupo Uninter e com a Prefeitura do município, um encontro presencial anual de todos os alunos matriculados em todos os cursos. Isso proporcionará aos alunos, um sentimento de pertencimento ao centro universitário e de realização por ter escolhido esse centro. 
Portanto, compreender o perfil do consumidor do Centro Universitário Uninter é uma tarefa complexa para os profissionais de marketing, pois cada consumidor age e pensa de maneira diferente, mas com a aplicação de uma pesquisa é possível definir seu perfil e começar a estudar estratégias para chegar até este público e instigá-lo a conhecer os cursos da Uninter e o próprio centro universitário para torná-los consumidores educacionais da Uninter - Polo de Palmeira das Missões/RS.

\section{REFERÊNCIAS}

Carvalho, A. (2013). Qualidade e educação a distância. Recuperado em 10 de abril, 2015, de http://www.administradores.com.br/artigos/academico/qualidade-eeducacao-a-distancia/74032/

Churchill Jr., G. A., \& Peter, J. P. (2007). Marketing: criando valor para os clientes. São Paulo: Saraiva.

Dias, S. R. (Coord.). (2003). Gestão de marketing. São Paulo: Saraiva.

Drubscky, L. (2015). Quais são as redes sociais mais usadas no Brasil? Recuperado em 10 de dezembro, 2015, de http://marketingdeconteudo.com/redes-sociais-mais-usadas-no-brasil/

Fachin, O. (2002). Fundamentos de metodologia (5a ed.). São Paulo: Saraiva.

Gerhardt, T. E., \& Silveira, D. T. (Orgs.). (2009). Métodos de pesquisa. Porto Alegre: Editora da UFRGS.

Gil, A. C. (1989). Métodos e técnicas de pesquisa social (2a ed.). São Paulo: Atlas.

Kotler, P., \& Armstrong, G. (2007). Princípios de marketing (12a ed.). São Paulo: Pearson Prentice Hall.

Lakatos, E. M., \& Marconi, M. de A. (2010). Fundamentos de metodologia científica (7a ed.). São Paulo: Atlas.

Las Casas, A. L. (2006). Marketing: conceitos, exercícios e casos (7a ed.). São Paulo: Atlas.

Limeira, T. M. V. (2008). Comportamento do consumidor brasileiro. São Paulo: Saraiva.

Matias-Pereira, J. (2012). Manual de metodologia da pesquisa científica (3a ed.). São Paulo: Atlas. 
Menezes, V. (2010). Comportamento do consumidor: fatores que influenciam o comportamento de compra e suas varáveis. Recuperado em 4 de junho, 2015, de http://www.administradores.com.br/artigos/marketing/comportamentodo-consumidor-fatores-que-influenciam-o-comportamento-de-compra-esuas-variaveis/47932/

Michel, M. H. (2009). Metodologia e pesquisa científica em ciências sociais (2a ed.). São Paulo: Atlas.

Ministério da Educação. (2015). Instituições de Educação Superior e Cursos Cadastrados. Recuperado em 2 de abril, 2015, de http://emec.mec.gov.br/

Nascimento, C. L., Jimenez, G. G., \& Campomar, M. C. (2014). A rede social como fonte de informação para o processo de decisão de compra. Future Studies Research Journal, 6(2), 31-47.

Oliveira, L. N. de. (2010). Comportamento do consumidor de educação superior a distância: análise das características influenciadoras e do processo de compra numa instituição baiana de ensino superior privado. Dissertação de Mestrado, Universidade Federal da Bahia: Salvador, BA, Brasil.

Paiva, R. (2012). Gestão de marketing educacional. Curitiba: IESDE Brasil.

Samara, B. S., \& Morsch, M. A. (2005). Comportamento do consumidor: conceitos e casos. São Paulo: Prentice Hall.

Schiffman, L. G., \& Kanuk, L. L. (2012). Comportamento do consumidor (9a ed.). Rio de Janeiro: LTC.

Silva, J. G. C. da. (2005). Métodos de pesquisa científica. Recuperado em 6 de junho, 2015, de http://www.academia.edu/3068793/Metodos_de_Pesquisa_Cientifica 